\title{
Study of Ecological Planning Method for Grassland Region Urban Green-space Systems in Inner Mongolia: A Case Study of Kangbashi, Ordos.
}

\author{
Jianxun Xing ${ }^{1, a}$, Chaoming $\mathrm{Li}^{2, \mathrm{~b}}$ \\ ${ }^{1,2}$ No.40 Aimin St, Xincheng District, Hohhot City, Inner Mongolia, China \\ 39073154@qq.com, ${ }^{\text {b }}$ chaomingli1004@gmail.com
}

Keywords: Green-space system, ecological problem, recovery mechanism, planning method.

\begin{abstract}
Establishing a mechanism of urban green-space planning and setting up an efficient ecological green-space systems for coping with fragile grassland ecological environment are urgently needed in Inner Mongolia region. This study chose Kangbashi as a research object to set to study as follows: identifying ecological problems of green-space environment in Kangbashi, analyzing regional ecological settings and status of urban and green space development. We pursued research from 5 aspects to demonstrate ecological planning method for grassland region urban green-space systems: establishing mechanisms such as ecological construction, environmental conservation and ecological recovery for mines, improving plant cultivation in urban green-space systems, enhancing construction and protection of green-space biodiversity. This study aims to explore a new ecological method for the urbanization of fragile ecological environment in frontier provinces.
\end{abstract}

\section{Identifying ecological problems}

Kangbashi new district is located at grassland desertification area, which is one of the fastest economic growth area in Inner Mongolia and has gained experiences by exploring construction of grassland urban green-space. However, in the process of rapid urbanization, there are many problems emerged during the construction of green-space, such as huge investment, high maintain cost and poor compound ecological function of green-space system. Ordos city, the capital of Kangbashi new district, has been seen as the vital zone of ecological conservation and restoration (Fig. 1), interior hinterland and soil erosion controlling area in north China, such as the middle and upper reaches of the Yellow River and Loess Plateau. In recent years, Kangbashi new district has achieved several goals in terms of conservation of water and soil, desertification control and nature reserve establishment. However, it still has several ecological environmental problems due to its weak ecological background. Therefore, in order to set up a correct and scientific goal, it demands an action of giving a priority of ecological background during the green-space planning process [1]. The ecological problems include several aspects as follows:

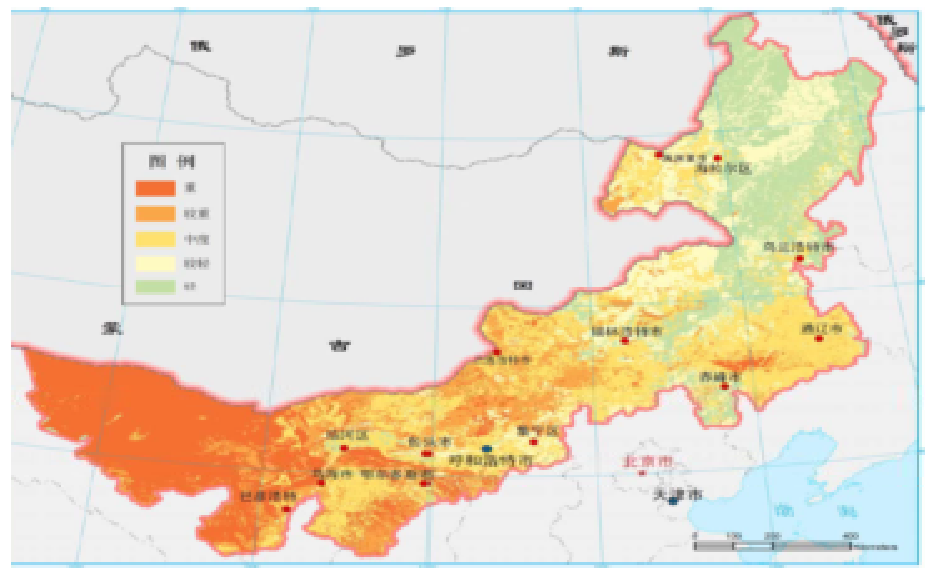

Fig. 1 Inner Mongolia ecological vulnerability assessment map 
Fragile ecological background, low vegetation coverage and severe soil erosion. Ecological system in grassland is relatively vulnerable and easy to be influenced by human activities so that the level of ecosystem services values is low. Kangbashi new district is seated in a typical grassland ecological system which is dominated by desertification grassland type of landscape and only $21.6 \%$ forest coverage distributed throughout the area of mountains and hills. Poor vegetation coverage will accelerate the pace of soil erosion so that this area is an vital part of water and soil erosion in Loess Plateau, which have huge impact on water quality and sediment deposition in Yellow River valley.

Severe grassland degradation and desertification. Kangbashi new district is located in low vegetation coverage area and mainly dominated by grassland of shortgrass type, which is a biochore with problems like low soil fertility, lack of rainfall, poor vegetation growth, poor soil quality, windy weather, grassland degradation, desertification and so forth. Meanwhile, the status of grassland degradation and desertification is difficult to manage as a result of human activities such as overgrazing, urbanization and mineral development.

Uneven distribution of water resources and salinization. Since annual precipitation concentrated in certain season, the rivers in Kangbashi new district and its surrounding areas are ephemeral streams, which will dry up during spring and winter and will cause seasonal water shortage. The city center of Kangbashi new district is rich in water resources and surrounded by abundant wetlands and rivers. However, water resources in inland river basin are insufficient. As as result, it can not afford massive artificial forests.

\section{Establishing the coordination mechanism of ecological construction and environmental protection.}

Ecological construction has been the first aim of Kangbashi' s urban development strategy. However, the lack of cooperation among the government branches during the ecological construction process leads to poor ecosystem performance. Therefore, when the stakeholders make an ecological plan of green-space system, it is necessary to include city' s vital ecological area into urban green-space system to form a green and ecological protective barrier. As the result, a holistic ecosystem will be built and the security of urban ecosystem will be improved [2].

Enhancing the protection of water source and ensuring the safety of urban drinking water. There are two types of water source in Kangbashi new district: urban underground water source and urban surface water source. They should be protected according to its type and define a reasonable ecological protective red line. Meanwhile, considering the protection of regional ecological water resource and enlarging the protective zone of water resource is the way to ensure the effect of implementation. The definition of underground water source should be coordinated with surrounding eco-forest, eco-pasture and eco-mountain land. On the other hand, the protection of surface water source should limit the urban development around the watershed. In particular, the construction of Wulanmu riverfront should limit development in order to protect the ecology. It is not only the important water resource in Kangbashi new district, but also the ecological watershed to downstream zone of Yulin city, Shanxi province. Therefore, the protection and usage of water resource should be considered from ecological aspect and break the barrier of local protectionism.

Reinforcing the conservation of ecological sensitive area, improving the safety level of regional ecosystem. The foundation of Kangbashi new district' s regional ecological security system consists of hills, rivers and wetlands, hence it should reinforce the conservation of this area by establishing natural reserve and improving its function of ecological service. It could combine the construction of city park, suburb park and scenic area to improve green coverage within urban area and build fully 
functional green-space system. Besides, it is necessary to enhance Kangbashi new district' $\mathrm{s}$ ecological sensitive area such as eco-grassland, forestry patch, Loess Plateau' s eco-corridor, farmland and so forth.

Enhancing ecological restoration and management, improving regional ecosystem condition. Because of its low vegetation coverage and hilly terrain, the natural condition in Kangbashi new district is abominable and it is easy to have the eco-problems such as desertification and soil erosion. Therefore, it should improve the restoration and management of damaged ecosystem in urban area by the method that combines breed naturally and artificial recovery. Meanwhile, combining soil and water conservation and desertification control, the condition of ecological environment will be restored as well. Ecological restoration is a gradual process of nature, which is a long cycle. Hence the general solution is to breed naturally first, artificial recovery second, instead of constructing green-space mindlessly. Basing on the theory of landscape ecological restoration, the application of ecological management will better improve the condition of regional ecosystem.

\section{Establishing ecological restoration mechanism for mineral area.}

There is no coal-mining area within Kangbashi new district, but it is noticed that there are mainly coal-mining area around city center according to the development and utilization plan of mineral resources (Fig. 2); it is shown that the north part of this area is geological disaster zone.

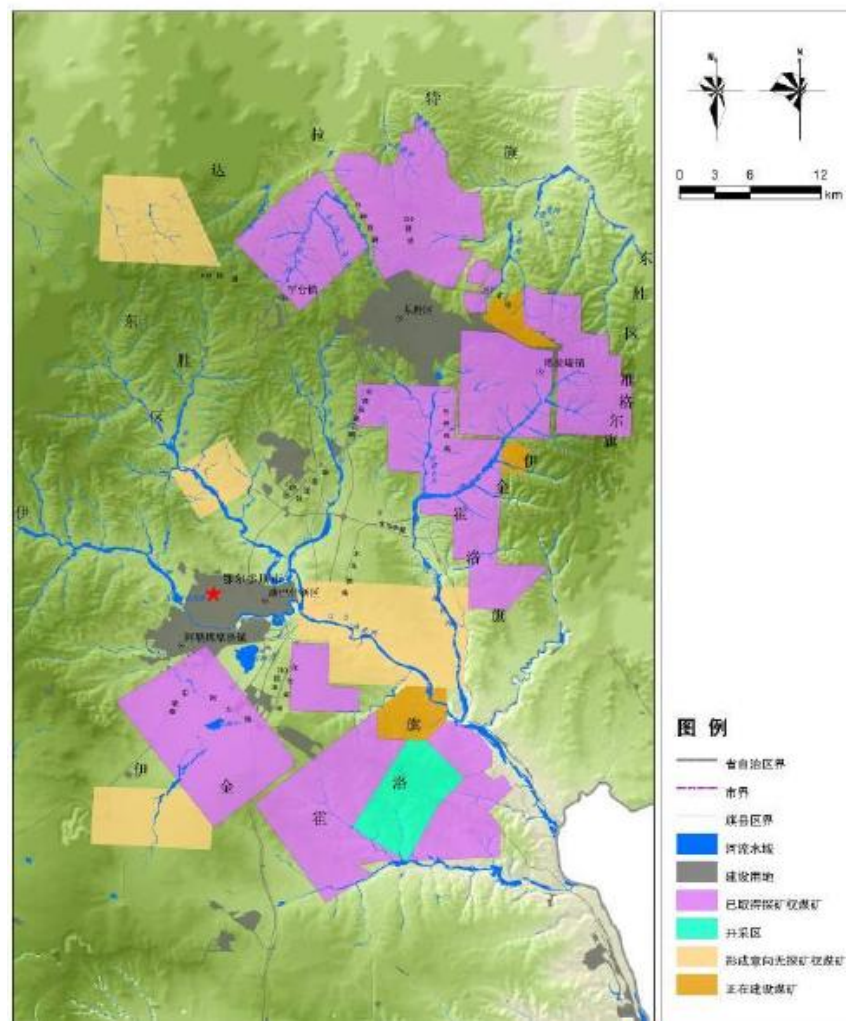

Fig. 2 Distribution map of mining area center city

Rigid limiting coal mining, applying comprehensive management for ecosystem of mining area. Coal mining is the main effect to regional urbanization, so it is essential to act under the rules of mining forbidden area to ensure a secure urbanization. Besides, it is important to enhance comprehensive management for areas like emptied mining area and collapse area. Making the use of vegetation and landscape potentials will restore ecological background. The construction of new mining area should meet environmental protective requirements in order to minimize the effects to the surrounding ecosystems. 
Comprehensive management for environment and ecological restoration. As mining areas near the new district are mainly located in vital sensitive ecological zone, it is hard to achieve a goal of sustainable environmental protection by managing and restoring the ecological environment of mining area. A comprehensive management for environment and ecological restoration is needed, so that the damaged ecological patches could re-integrate into ecological corridor and matrix, then the ecosystem will recover [3].

Land use pattern with thoughts on local conditions. For the emptied mining area around the urban settings, a completely research on its background stability and surface coverage situation is needed, and a land use pattern with thoughts on local conditions will meet the needs of ecological restoration and reviving urban energy. The exposed mining areas are mainly located at bottom field, which can combine with surrounding watershed to form an artificial lake or wetland park. Besides, the flat areas can be developed as leisure space like suburban park, and complex terrains could be constructed as forestry park and post industrial park. Finally, for the underground mining areas with good geological condition, they can be built as theme park like mining adventure and geological park [4].

\section{Improving plants arrangement within urban green-space system}

The plants arrangement of green-space system in Kangbashi new district is fully expressed on many aspects, such as spatial level and landscape performance. However, the arrangement is lack of attention of ecological concern, which do not fully consider about the construction of grassland ecological patche and plant biome, so that it needs artificial maintenance instead of ecological self-adjustment. Vegetation is the base background to green-space system and plants arrangement is vital for the ecological construction of green-space system.

Establishing reasonable vegetation structure. The construction of urban green-space needs abundant plant types to reflect its high landscape quality. The plants in the Kangbashi new district mainly consist of trees and shrubs, but its plant stability is poor and needs high maintenance. Therefore, it is necessary to combine trees, shrubs, herbaceous and meadows to enhance landscape amenity and ecological functions.

Reinforcing indigenous plant and making use of different types of plant to define space. Basing on Kangbashi new district' s existing plant arrangement, it needs to highlight city characteristic by placing several huge trees and using indigenous species. Because of its complex geological conditions, the plant species in grassland region has more resistance characteristics. In recent years, along with domestication of grassland species, indigenous plants have been applied into urban green-space construction. These plants have better capacity of ecological restoration, which can support sustainable urban landscape design and form an obvious local characteristic.

\section{Reinforcing protection and construction of biodiversity in green-space}

The protection of urban vegetation biodiversity can promote the exchange of genetic genes. Increasing plant species within urban area can improve the stability of urban vegetation, which is good for the development of urban green-space. There are several methods of urban plant biodiversity protection: on-site conservation, off-site conservation and ecosystem restoration. On-site and off-site conservation are more suitable for Kangbashi new district. On-site conservation is making use of natural reserve to protect natural ecosystem. Off-site conservation is based on urban landscape and botanical garden to protect biodiversity as a supplement for on-site conservation, which is suitable for the emergency measures of endangered species. Meanwhile, it is the call for urban development that needs to integrate biodiversity protection into the future regional planning. Biodiversity conservation 
includes four aspects: genetic diversity conservation, species diversity conservation, ecosystem diversity conservation and landscape diversity conservation. The biodiversity conservation of green-space system needs a series of census: regional biodiversity census, urban green-space biodiversity census and suburb green-space biodiversity census. By doing so, a harmony, stable and health ecosystem will be built and a better habitat and environment will be created. As a result, human, nature and urban will have a sustainable development [5].

\section{The levels and plans of green-space biodiversity conservation}

The green-space biodiversity conservation of Kangbashi new district is mainly about the conservation on three aspects: genetic, species and ecosystem (Fig. 3).

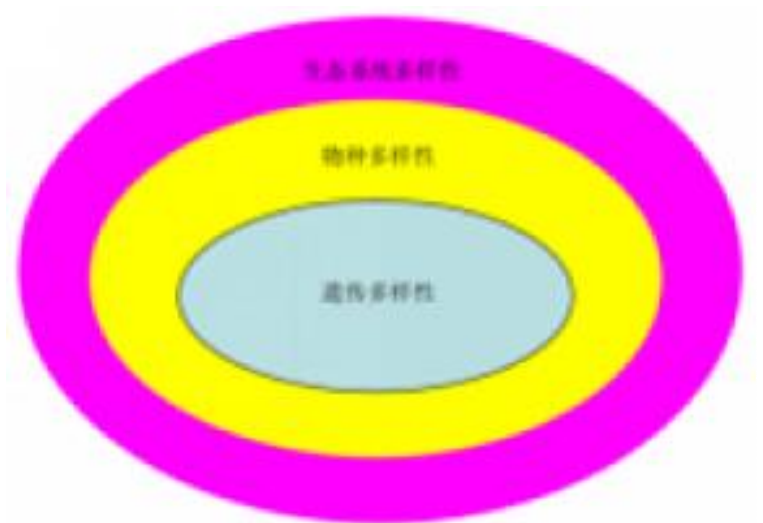

Fig. 3 Biodiversity hierarchy diagram

The plan of genetic diversity conservation. It should enhance the reserve construction and protect good variety resource. The three genetic resource conservation systems should be established: crop species conservation, livestock species conservation and endangered plant species conservation. Basing on Ordos reserves, it should reinforce the protection for psammophytes like Hippophae rhamnoides, apricot, Salix mongolica, licorice, sacsaoul and Herba cistanches. Meanwhile, the indigenous plant species should be protected as well, such as Tetraena mongolica, Ammopiptanthus mongolicus, Potaninia mongolica, Labdane and Calligonum mongolicum. The conservation of endangered birds is as important as other species, such as Larus relictus, Anatidae, Accipitridae, Sylviinae and Charadriidae. It is necessary to make use of botanical garden to improve urban image. By establishing demonstrated green-space using well-known Chinese herbs, well-known fruits, landscape plants, well-known wild vegetables and endangered vegetation, the reputation of indigenous species will be spread and draw attention to consciousness of biodiversity conservation [6].

The construction and conservation of biodiversity. The main urban area needs to build multi-level botanical garden, which plants vegetation on purpose and has initial function of species preservation. Hence applying botanical garden is a way to improve plant diversity. One of the most important aspects of plant preservation is the construction of off-site botanical garden conservation base, which is a project that is about enlarging the area of botanical garden and establishing several theme botanical parks. Meanwhile, it also should build the monitor and evaluation systems of landscaping vegetation.

Ecosystem diversity construction and conservation. In order to preserve ecosystem diversity, we divide the ecosystem of Kangbashi new district into three areas basing on the effects of natural and semi-natural ecosystem to the resilience of urban construction: Key development area and general development area (buildable landuse), limited development area(secondary buildable landuse) and 
ecological conservation area(unbuildable landuse). 1. Key development area and general development area mainly consists of urban compact area, agriculture area and production and living area. This type of area is mainly about non-ecological sensitive area and low sensitive area that include new development area and reserving construction land. In order to integrate urbanization and ecological resilience, this type of green-space should cope with the relationship between urbanization and ecological conservation during the development. limited development area consists of ecological control green-space and ecological restoration green-space. 2. Ecological control green-space is mainly about the seismic fault lines that cross urban area. Because of its dangers to urban environment, its land use needs to be controlled as green-space to ensure the safety of human activities within urban area; Basic farmland protection area mainly consist of agriculture economy and other aspects like forestation, herding, fishing and third industry. By limiting the occupation of farmland to ensure the dimension of farmland area, the ecological environment conservation is reinforced in farmland protection area. 3. The ecological conservation area is the areas within urban area that include reserves, underground water conservation areas and wetlands. Reserve is the foundation of ecosystem and species, which requires a good relationship between preservation and tourism. Underground water conservation area is to build a green barrier to separate water source from external threat and to integrate with surrounding green background to form a holistic ecological spatial pattern. Urban wetland ecosystem in Kangbashi new district includes rivers and lakes, which can make use of rainfall to build artificial wetland, ecological basin to purify water. Besides, increasing the use of aquatic plant can attract wildlife and improve biodiversity, which is good for a better urban wetland ecological environment.

\section{Conclusions}

The typical ecological type in Inner Mongolia is grassland ecosystem, which has a fragile ecological environment. Grassland urban green-space is the vital green infrastructure for the sustainable development of grassland ecological environment and more constructions of urban greening are in progress along with Inner Mongolia's rapid urbanization. The study of ecological planning method can coordinate the relationship between artificial green-space and grassland natural ecological environment within grassland cities, which will highlight local characteristic and boost the sustainable development of grassland urbanization. As the result, a brand new development train of thought of Inner Mongolia ecological civilization is demonstrated.

\section{Acknowledgement}

This work was financially supported by the Science Research Program of Inner Mongolia University of Technology (X201331).

\section{References}

[1] S. Liu, Y. Liu and Q. wen: Urban Green Space System Planning (China Architecture \& Building Press, Beijng 2011), p.43-50

[2] J.shen: Urban Ecological Environment: Principle, Method and Optimization (China Architecture \& Building Press, Beijng 2011), p.534-537.

[3] S,wang: The Landscape Planning Design Research of Suburban Area Green Space (Beijing Forestry University, 2012), p11-12

[4] J. Ahern and X. Zahou: Greenway Planning Theory and Methods. Landscape Architecture, Vol. 5 (2011), p.104-107

[5] Information on http://www.ordosgh.gov.cn/ghzss/ztgh/201706/t20170613_1965813.html 
[6] Information on

http://www.ordosgh.gov.cn/wx/spgs_94097/pqgs_94098/201606/t20160618_1701638.html 